\title{
PELATIHAN KETERAMPILAN MAKRAME BAGI IBU-IBU RUMAH TANGGA DI KELURAHAN LINGKAR BARAT KOTA BENGKULU
}

\section{MAKRAME SKILLS TRAINING FOR HOUSEWIVES IN LINGKAR BARAT SUB-DISTRICT, BENGKULU CITY}

\author{
Oleh \\ Dwi Anggraini, Hasnawati, Dalifa \\ PGSD FKIP Universitas Bengkulu \\ Email: dwianggraini@unib.ac.id
}

\begin{abstract}
This training is motivated by the situation of housewives who spend time with less useful activities. On the other hand, making bags and wallets by using makrame techniques is developing in the community. For that, it is necessary to provide training to housewives to increase knowledge and skills about makrame. The method used is training which is divided into two stages, namely the stage of giving material and practice guided by the PPM team and six tutors. Increased knowledge is obtained from the difference in scores of participants after pretest and post-test. The results of the pre-test showed that only eightparticipants $(25.8 \%)$ who received a score of $\geq 60$, at post-test increased to 22 participants (70.97\%) who received a score of $\geq 60$. The conclusion of this activity is the knowledge and skills of the trainees increased.
\end{abstract}

Keywords: Makrame, Art, Skills, Housewives

\section{PENDAHULUAN}

Saat ini di media sosial banyak informasi tentang cara membuat tas, dompet, gantungan dinding, kerai pintu ataupun jendela dari tali kur. Keterampilan membuat benda menggunakan tali kur ini disebut dengan makrame. Makrame adalah salah satu cabang seni rupa yang merupakan teknik tekstil tertua yang dibuat dengan cara menyimpul beberapa tali maupun benang menjadi suatu bentuk berpola dekoratif-geometrik (Asriyani, 2013).

Makrame merupakan keterampilan yang menarik dan dapat mengembangkan kreativitas, tidak membutuhkan biaya yang banyak, hanya membutuhkan ketekunan dan keuletan (Muthi'ah, 2013). Hal ini sangat cocok apabila dilatihkan pada ibu-ibu rumah tangga yang saat ini lebih banyak menghabiskan waktu dengan "mengutak-atik" handphone (HP) dibandingkan menggunakan tangannya untuk mengembangkan kreativitas. Selain itu, mereka juga suka berkumpul tanpa melakukan aktivitas yang bermanfaat.

Terkait dengan persoalan di atas, Trisnawati dkk (2018) dalam artikelnya yang berjudul "Pelatihan Membuat Tas Makrame Bagi Remaja Putus Sekolah di UPTD Bina Harapan Remaja Kota Padang Panjang" mengungkapkan bahwa pelatihan makrame ini dapat meningkatkan pengetahuan dan keterampilan remaja di UPTD Bina Harapan Remaja Kota Padang Panjang.

Keterampilan makrame juga dapat menambah income generating. Pembuatan keterampilan makrame dengan model yang unik dan pemilihan warna yang menarik akan diminati oleh masyarakat. Ditambah lagi jika dikemas menggunakan packaging yang 
menarik. Tentunya hal ini dapat mengembangkan kreativitas sekaligus menambah uang belanja ibu-ibu rumah tangga, khususnya bagi ibu-ibu rumah tangga di Komplek Pepabri RT 14 dan RT 18 kelurahan Lingkar Barat Bengkulu. Hartati dan Kurniasari (2017), mengungkapkan bahwa setelah mendapatkan pelatihan kewirausahaan dan membuat tas dari tali kur dengan menggunakan teknik makrame, mahasiswa memiliki pemahaman tentang kewirausahaan dan jenis usaha yang berbasis kreativitas dan kerajinan tangan, salah satunya yaitu membuat tas dari tali kur dengan menggunakan teknik makrame.

Ibu-ibu rumah tangga di Komplek Pepabri RT 14 dan RT 18 Kelurahan Lingkar Barat banyak menghabiskan waktu luangnya dengan berkumpul dan mengobrol. Hal ini terkesan membuang-buang waktu dengan kegiatan yang tidak bermanfaat. Di lain sisi, kebutuhan rumah tangga dan kebutuhan pribadi sebagai wanita sangat banyak. Sehingga diperlukan tambahan uang untuk memenuhi kebutuhan tersebut. Sebagai wanita, ibu-ibu rumah tangga memerlukan kegiatan agar kebutuhan tersebut dapat terpenuhi secara mandiri tanpa meminta uang tambahan dari suami. Untuk itu dirasa sangat penting untuk diadakannya pelatihan keterampilan makrame bagi ibu-ibu rumah tangga di Komplek Pepabri RT 14 dan RT 18Kelurahan Lingkar Barat Kota Bengkulu, mengingat manfaat yang didapatkan melalui pelatihan ini sangat besar, maka diharapkan pelatihan dapat segera dilaksanakan agar mereka mendapatkan pengetahuan dan keterampilan tentang makrame dan memanfaatkan keterampilan tersebut untuk menambah income generating.

\section{METODE PENGABDIAN}

Kegiatan ini dilaksanakan sebanyak dua kali pertemuan, yaitu tanggal 29 Juli 2018 dan 5 Agustus 2018 pada 31orang ibu-ibu rumah tangga RT 14 dan RT 18 di Kelurahan Lingkar Barat Kota Bengkulu. Metode yang digunakan yaitu pelatihan yang dibagi menjadi dua tahapan yaitu tahap pemberian materi dan praktik pembuatan dompet makrame.

Penyampaian materi mencakup teori-teori dan segala sesuatu terkait dengan makrame, seperti sejarah, simpul-simpil yang digunakan dalam makrame, alat dan bahan, serta contoh-contoh karya seni makrame. Setelah mendapatkan materi, tim PPM menyajikan vidoe tutorial cara menyimpul simpul persegi/simpul dasar dan simpul kait ganda/simpul lilit. Kemudian peserta dibagi menjadi enam kelompok untuk praktik membuat dompet makrame yang dipimpin oleh satu orang tutor per kelompok. Praktik membuat dompet makrame tidak dapat diselesaikan dalam satu kali pertemuan, maka peserta diperkenankan untuk melanjutkan pekerjaannya di rumah dan membawanya kembali pada pertemuan berikutnya. Disela pertemuan (berjarak satu minggu), tim PPM memonitoring untuk melihat perkembangan peserta dalam membuat dompet makrame.

Teknik pengumpulan data yang digunakan yaitu observasi untuk mengamati proses kegiatan pelatihan dimulai dari pemberian materi hingga praktik. Selain observasi, tes juga dilakukan untuk mengukur tingkat pengetahuan peserta tentang makrame yang dilakukan sebanyak dua tahap, yaitu sebelum diberikan pelatihan (pre-test) dan setelah pelatihan diberikan (pos-test). 


\section{HASIL DAN PEMBAHASAN}

\section{Observasi Proses Pembuatan Dompet Makrame dari Tali Kur}

\section{Pemberian Materi Makrame}

Pelatihan keterampilan membuat dompet dari tali kur menggunakan teknik makrame dilaksanakan selama dua hari, yaitu hari 29 Juli 2018 dan 5 Agustus 2018 di gedung PNPM Komplek Pepabri Lingkar Barat. Kegiatan pelatihan ini diikuti oleh 31 orang peserta yaitu ibu-ibu rumah tangga RT 14 dan RT 18 Kelurahan Lingkar Barat Bengkulu, dengan dibantu oleh 6 orang mahasiswa PGSD Universitas Bengkulu sebagai tutor yang telah dilatih sebelumnya. Kegiatan ini dibagi menjadi dua tahapan yaitu pemberian materi dan praktik membuat dompet dengan menggunakan teknik makrame. Sebelum pemberian materi, diadakan acara pembukaan yang dibuka secara resmi yang diwakili oleh ibu Ketua RT 14 Kelurahan Lingkar Barat.

Pada tahap pertama dilaksanakan pada hari Minggu tanggal 29 Juli 2018 pukul 08.00 WIB s/d12.00 WIB. Tim PPM memberikan materi yang berkaitan dengan pengertian dan sejarah makrame, jenis-jenis simpul dan karya atau benda yang dapat dibuat dengan menggunakan teknik makrame. Pada tahap ini, peserta mendengarkan materi yang disampaikan oleh tim PPM dan dilakukan tanya jawab mengenai materi yang diberikan. Peserta tampak antusias. Makrame atau masyarakat umum mengenalnya dengan sebutan menyimpul menggunakan tali merupakan sesuatu yang sekarang sedang menjadi trend di masyarakat. Banyak orang menggunakan tas, dompet, gantungan dan aksesoris dari tali kuryang disimpul. Namun mereka belum mengetahui asal mula makrame tersebut.

\section{Praktik Membuat Dompet Menggunakan Teknik Makrame}

Pada tahap kedua yaitu praktik membuat dompet. Sebelumnya, Tim PPM membagi peserta menjadi lima kelompok dan menempatkan satu orang tutor pada tiap-tiap kelompok. Setiap peserta telah mendapatkan alat dan bahan seperti tali (2 meter), inner dompet $(20 \mathrm{~cm} \times 10 \mathrm{~cm})$, jarum dan benang.

Tim PPM mempraktikkan terlebih dahulu macam-macam simpul yang akan digunakan dalam membuat dompet dan juga yang sering digunakan dalam membuat tas. Adapun simpul yang digunakan yaitu simpul persegi (simpul dasar) dan simpul kait ganda (simpul lilit). Tim PPM mempratikkan simpul-simpul tersebut dengan menggunakan bantuan tayangan video tutorial yang telah dibuat sebelumnya. Namun penggunaan media video untuk menyampaikan materi simpul kurang efektif. Dengan kondisi seperti ini, keberadaan tutor dalam tiap kelompok sangat membantu.

Pada tahap awal peserta membuat simpul dasar sebanyak 14 buah sebagai kepala dompet. 14 buah kepala tersebut terdiri dari 2 warna ungu/abu-abu dan 12 warna hitam. Simpul kepala yang sudah jadi kemudian disusun berjejer, dan dilanjutkan dengan menggabungkan simpul-simpil tersebut dengan menggunakan simpul dasar. Proses ini sudah di dampingi oleh tim PPM dan tutor. 

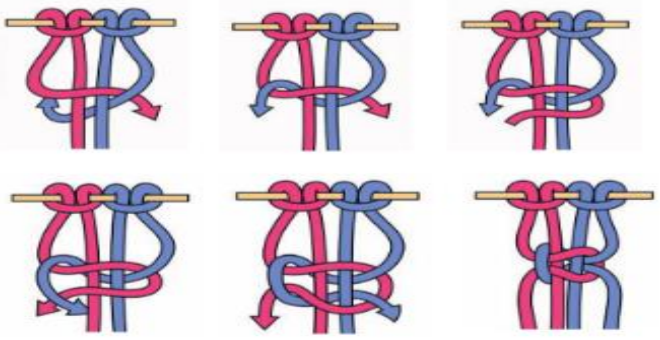

Gambar 1. Square Knot (Simpul

Persegi) (Asriyani, 2013)

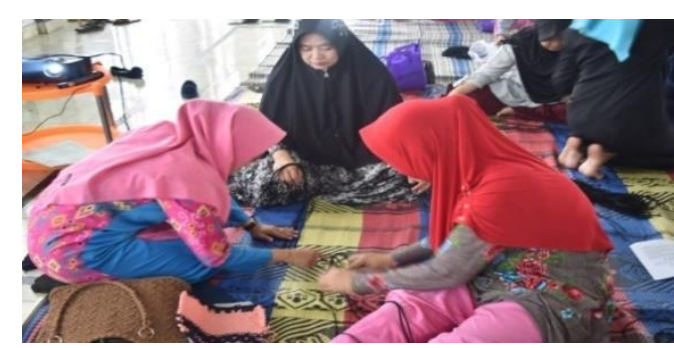

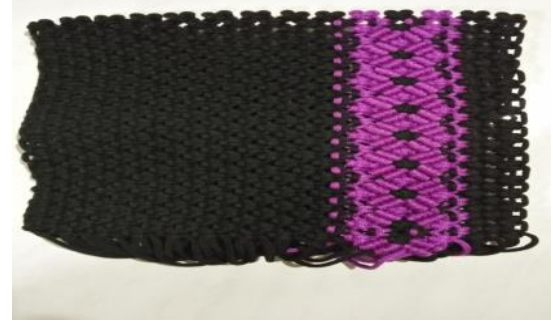

Gambar 2. Simpul Berbentuk Tikar Sebelum Disatukan dengan Inner Instan (Sumber: dokumentasi Dwi Anggraini)

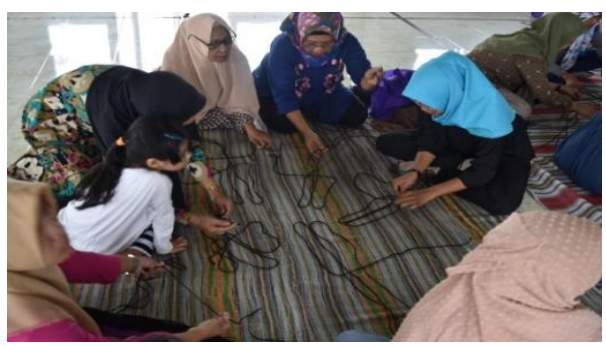

Gambar 3. Pendampingan Tim PPM dan Tutor kepada Peserta Pelatihan dalam Membuat Simpul Persegi (Kepala) (Sumber: Dokumentasi Dwi Anggraini)

Dalam membuat dompet dengan inner instan ini dibuat dengan teknik tikar. Saat membuat kepala, hampir seluruh peserta dapat membuat kepala dengan mudah. Kepala dibuat menggunakan simpul persegi atau simpul dasar. Pada saat menyatukan dua buah kepala dengan simpul dasar, peserta mulai mengalami kesulitan. Peserta tidak konsisten melihat posisi tali yang akan disimpul, sehingga perlu beberapa kali bongkar pasang simpul. Namun demikian, peserta tetap memperbaiki simpul yang dibuat agar sesuai dengan yang diharapkan. Setelah tiga tingkat simpul dasar (dari kepala samai simpul dasar), selanjutnya adalah menentukan tulang untuk melilitkan simpul kait ganda (simpul lilit) untuk membuat motif bunga melati pada dompet. Simpul kait ganda dilakukan berlawanan. Pada tahap ini hampir seluruh peserta merasa kesulitan dalam menentukan tulang dan melilitkan tali kur. Rata-rata mereka kesulitan memutuskan tali yang benar untuk dijadikan tulang dan melakukan lilitan yang benar (ke kiri atau ke kanan).

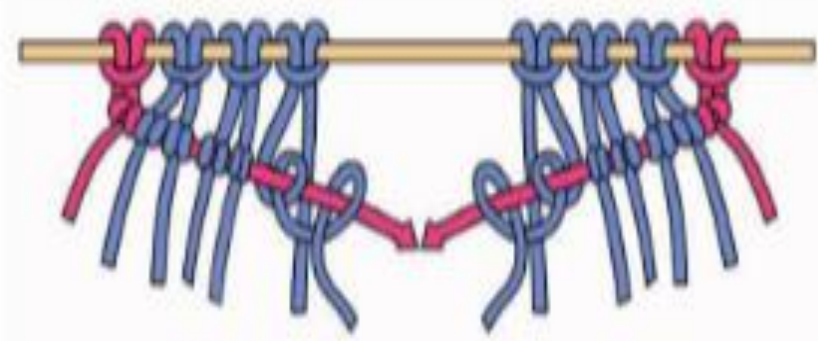

Gambar 4. DoubleHalf Hitch (Simpul Kait Ganda) (Asriyani, 2013)

Pertemuan hari Minggu tanggal 29 Juli 2018 selesai pada pukul 12.00 WIB. Namun peserta belum berkeinginan beranjak dari tempat duduknya dikarenakan sedang asyik 
membuat simpul. Peserta yang belum menyelesaikan simpulnya wajib menyelesaikan simpulnya di rumah.

Selama peserta melakukan praktik membuat dompet,tim PPM melakukan pengamatan terhadap perkembangan keterampilan peserta. Tim melihat bahwa sebagian besar peserta mampu membuat simpul dasar awal (kepala) dan menyambungkan setiap kepala menjadi rangkaian utuh. Namun untuk menyimpul pada langkah selanjutnya, ada beberapa peserta yang sulit menemukan alur menyimpul sehingga harus selalu bertanya dengan tim. Walaupun demikian, ada juga beberapa orang peserta yang dengan mudah dapat memahami alur simpul dompet dan dapat menyelesaikan kegiatan menyimpul dengan baik.

Tim PPM memonitoring kerja peserta yang diselesaikan di rumah. Pada hari Selasa tanggal 31 Juli 2018 pukul 16.00 WIB, tim PPM mengumpulkan kembali peserta pelatihan di gedung PNPM untuk memantau perkembangan tugas yang telah diberikan. Kesulitan menentukan tulang untuk dijadikan motif tidak lagi dialami kebanyakan peserta, namun masih ada juga peserta yang kesulitan.

Pertemuan kedua dilaksanakan pada tanggal 5 Agustus 2018 pukul 13.00 WIB di gedung PNPM. Pada tahap ini, tim PPM membagikan inner dompet yang telah disediakan. Inner dompet ini merupakan inner instan berukuran $20 \times 10 \mathrm{~cm}$. setelah semua peserta mendapatkan inner, mereka mencocokkan simpul yang telah dibuat dengan inner yang didapat. Peserta yang menyimpul terlampau panjang, maka harus membuka kembali simpul tersebut agar sesuai dengan inner. Begitupun sebaliknya, peserta yang menyimpul namun belum sesuai dengan ukuran inner, maka harus menambah simpul terlebih dahulu.

Setelah semua peserta menyesuaikan antara simpul dan inner, tim PPM membagikan gunting, korek, jarum, dan benang. Gunting digunakan untuk menggunting sisa tali kur yang terlampau panjang, korek digunakan untuk membakar dan mengelem tali yang sudah dipotong tadi agar tidak berantakan, serta jarum dan benang untuk menjahitkan atau menyatukan inner dan simpul. Pada saat menjahit, peserta lebih mudah melakukannya dibandingkan dengan membuat simpul. Peserta degan sigap mampu menyatukan simpul dan dompet, walaupun sesekali ada beberapa peserta yang bertanya karena tidak berani mengambil keputusan tentang cara menjahit inner dompet.

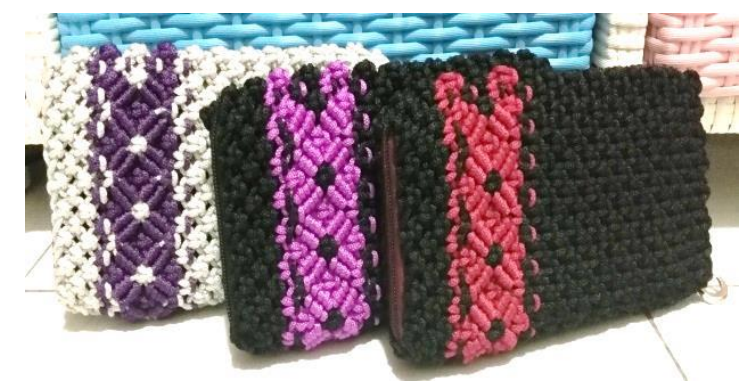

Gambar 5. Dompet Makrame

(Sumber: dokumentasi Dwi Anggraini)

\section{Tes}

Untuk mengukur pengetahuan peserta pelatihan membuat dompet berbahan tali kur menggunakan teknik makrame dilakukan tes sebanyak dua tahap. Tahap pertama tes dilakukan sebelum pelatihan dimulai (pre-test) dan tahap kedua setelah pelatihan dilaksanakan (post-test). 
Berdasarkan pengolahan data, hasil tes dapat dirincikan pada tabel berikut ini.

Tabel 1. Persentase Hasil Pre-test Guru Sasaran

\begin{tabular}{cccc}
\hline No & Kriteria & Jumlah Guru & Persentase \\
\hline $\mathbf{1}$ & $\geq 60$ & 8 & $25,8 \%$ \\
$\mathbf{2}$ & $\leq 59$ & 23 & $74,19 \%$ \\
\hline
\end{tabular}

Berdasarkan tabel di atas, dapat dilihat bahwa sebagian besar peserta belum mengetahui tentang sejarah dan seluk beluk tentang karya makrame. Hal ini terlihat lebih dari $50 \%$ peserta mendapat nilai $\leq 59$. Setelah diberikan pre-test, peserta diberikan materi tentang makrame serta praktik membuat karya makrame berupa dompet dengan menggunakan bahan tali kur. Di akhir kegiatan peserta diberikan posttest untuk melihat tingkat keberhasilan pengetahuan peserta terhadap keterampilan makrame. Adapun hasil post-test dapat dilihat pada tabel berikut ini.

Tabel 2. Persentase Hasil Post-test Guru Sasaran

\begin{tabular}{cccc}
\hline No & Kriteria & Jumlah Guru & Persentase \\
\hline $\mathbf{1}$ & $\geq 60$ & 22 & $70,97 \%$ \\
$\mathbf{2}$ & $\leq 59$ & 9 & $29,03 \%$ \\
\hline
\end{tabular}

Berdasarkan tabel di atas, dapat dilihat bahwa lebih dari $50 \%$ peserta pelatihan mencapai nilai $\geq 60$, artinya guru sasaran sudah memahami tentang segala sesuatu tentang karya makrame.

\section{Pembahasan}

Makrame merupakan istilah yang baru bagi khalayak sasaran kegiatan PPM ini, tetapi tidak untuk kerajinan membuat tas, dompet atau segala sesuatu yang berkaitan dengan tali kur. Kerajinan makrame dapat digunakan sebagai benda fungsional berupa aksesori (aksesori rumah/aksesori busana) (Sartini, 2011). Seperti halnya kerajinan membuat tas atau dompet dengan menggunakan tali kur sebagai bahan utama sudah banyak diminati khalayak ramai dan sudah ada komunitas yang memfailitasi untuk mengadakan pelatihannya dengan membayar sejumlah biaya. Hanya saja peserta belum memiliki kesempatan dan biaya untuk mengikuti pelatihan. Hal ini dikarenakan biaya pelatihan tersebut tergolong mahal untuk ibu-ibu rumah tangga dengan kelas ekonomi menengah ke bawah. Oleh sebab itu, peserta pelatihan sangat antusias dengan adanya pelatihan membuat dompet dari tali kur dengan menggunakan teknik makrame.

Makrame merupakan bagian dari seni rupa. Makrame menggunakan unsur seni rupa yang dapat dinikmati oleh mata dan diapresasi. Hal ini sejalan dengan pendapat Sumanto (2011), yang mengatakan bawa seni rupa merupakan cabang seni yang penciptaanya menggunakan elemen atau unsur seni rupa dan dapat diapresiasi oleh panca indera. Dalam hal ini, makrame merupakan seni rupa terapan (yang dapat digunakan dalam kehidupan sehari-hari) yang termasuk dalam seni kerajinan/kria.

Berdasarkan hasil observasi, pengetahuan dan keterampilan peserta dalam membuat karya makrame meningkat. Hal ini dibuktikan dengan adanya pretest dan post-test yang diberikan kepada khalayak sasaran. Hasil pretest menunjukkan lebih $50 \%$ peserta belum memiliki pengetahuan tentang makrame. Hal ini dapat dirincikan sebagai berikut: (1) sebanyak 8 orang peserta atau $25,8 \%$ mendapat skor $\geq 60$, dan (2) sebanyak 23 orang peserta atau 74,19\% mendapat skor $\leq 59$. Setelah diberikan materi pelatihan dan praktiknya, terdapat peningkatan hasil tes, yaitu lebih dari 50\% telah memiliki pengetahuan tentang makrame dengan rincian sebai berikut: (1) sebanyak 22 orang peserta 
atau $70,97 \%$ mendapat skor $\geq 60$, dan (2) sebanyak 9 orang peserta atau $29,03 \%$ mendapat skor $\leq 59$. Dengan demikian pengetahuan peserta terhadap makrame meningkat sebanyak $45,17 \%$.

Setelah mendapatkan materi, peserta kemudian praktik membuat karya makrame yaitu dompet. Menurut Soemarjadi (1992), proses pembuatan karya makrame terdiri dari proses periapan desain motif, persiapan bahan, persiapan alat dan terakhir proses menyimpul. Tahap pertama yaitu menentukan motif. Motif yang dibuat yatu motif melai. Motif ini ditentukan oleh tim PPM. Tim memilihkan motif yang sedikit dan sederhana. Karena peserta belum mengetahui motif apa yang mudah untuk pemula. Tahap kedua yaitu menyiapkan alat dan bajan. Adapun bahan yang digunakan yaitu tali kur (warna hitam ungu dan hitam abu-abu) dan inner instan. Alat yang digunakan yaitu jarum dengan ukuran besar, benang, gunting, dan korek api. Karya yang dibuat yaitu dompet.

Langkah selanjutnya yaitu membuat simpul. Untuk membuat motif melati simpul yang digunakan yaitu simpul kait ganda/simpul lilit dan juga simpul persegi/simpul dasar. Namun secara keseluruhan simpul yang dominan digunakan yaitu simpul persegi/dasar. Simpul kait ganda berperan membentuk motif. Langkah terakhir adalah finishing yaitu menyatukan tali kur yang telah disimpul dengan inner instant yang sudah disiapkan.

Simpul-simpul tali kur membentuk garis. Pada karya makrame dompet yang dibuat, garis yang digunakan yaitu garis lengkung dan garis lurus. Menurut Aminuddin (2009), garis terdiri dari garis lurus (berkesan tegas dan keras), garis lengkung (berkesan lembut dan lentur), dan garis spiral atau pilin (berkesan luwes). Garis lurus terlihat pada pola bunga melati (warna ungu/abu-abu) dan garis-garis yang diciptakan antara simpul persegi.

Selain garis, karya makrame menggunakan warna, antara lain hitam, abu-abu dan ungu. Warna-warna yang digunakan tidak tergolong pada warna primer. Karena menurut Aminuddin (2009), warna primer terdiri dari kuning, merah dan biru. Sedangkan warna sekunder adalah perpaduan dari dua warna seperti hijau, ungu dan lain sebagainya.

Pada karya dompet makrame yang dibuat, tekstur dompet dapat terasa. Tekstur semacam ini disebut dengan tekstur nyata, yaitu tekstur yang dimiliki oleh sebuah hasil karya seni antara indera peraba dan penglihatan terasa sama. Tekstur merupakan sifat dan keadaan permukaan bidang benda (Kamaril, 2006). Tekstur dompet makrame cenderung kasar atau tergantung pada tekstur tali kurnya.

\section{KESIMPULAN DAN SARAN}

\section{Kesimpulan}

Berdasarkan pelatihan yang telah dilaksanakan dapat disimpulkan sebagai berikut.

a. Ibu-ibu rumah tangga RT 14 dan RT 18 Kelurahan Lingkar Barat Bengkulu memiliki pengetahuan tentang makrame.

b. Ibu-ibu rumah tangga RT 14 dan RT 18 Kelurahan Lingkar Barat Bengkulu memiliki keterampilan dalam membuat dompet menggunakan teknik makrame.

\section{Saran}

Adapun saran yang dapat diberikan berdasarkan kegiatan pelatihan yang telah dilaksanakan adalah sebagai berikut.

a. Keterampilan makrame membutuhkan teknik dan keterampilan yang baik. Dengan demikian, dibutuhkan waktu yang banyak agar peserta mahir dalam membuat keterampilan makrame. 
b. Jika menggunakan inner instan, maka sebaiknya inner tersebut diberikan di awal pelatihan agar peserta dapat menentukan seberapa banyak simpul yang perlu dibuat untuk membuat dompet dengan menggunakan inner instan. Hal ini lebih efektif agar tidak terjadi bongkar pasang dalam menyimpul.

\section{DAFTAR PUSTAKA}

Aminuddin, 2009, Apresiasi dan Ekspresi Seni Rupa, Bandung: Puri Pustaka.

Asriyani, I, 2013, Inspirasi Makrame,Surabaya: Tiara Aksa.

Hartati, I, \& Kurniasari, L. (2018). Penumbuhkembangan jiwa kewirausahaan mahasiswa melalui pelatihan teknik dasar makrame dalam pembuatan tas dari talikur. Abdimas Unwahas, 2(1).

Kamaril, C, 2006, Pendidikan Seni Rupa/Kerajinan Tangan, Modul Universitas Terbuka. Jakarta: Universitas Terbuka.

Muthi'ah, W, 2013, Teknik Makrame Dalam Tren Fashion, Jurnal Serat Rupa, Vol. 1, Hal 35-46.

Sartini, 2011, Pengembangan Modul Kerajinan Makrame Untuk Pembelajaran Keterampilan PKK Di SMP Negeri 1 Yogyakarta, Laporan Penelitian, Program Studi Pendidikan Teknik Busana Universitas Negeri Yogyakarta.

Soemarjadi, Ramanto, M, \& Zahri, W, 1992, Pendidikan Keterampilan, Departemen Pendidikan dan Kebudayaan Direktorat Jendral Pendidikan Tinggi Proyek Pembinaan Tenaga Kerja Kependidikan.

Sumanto, 2011, Pendidikan Seni Rupa Di Sekolah Dasar, Malang: Fakultas Ilmu Pendidikan Universitas Negeri Malang.

Trisnawati, D, Ranelis, R., Wendra, W, Prasilia, L, Ediantes, E, 2018, Pelatihan Membuat Tas Makrame bagi Remaja Putus Sekolah Di UPTD Bina Harapan Remaja Kota Padang Panjang, Batoboh, 3(2), 128-136. 


\section{Lampiran}

\section{SOAL PRETEST/ POSTEST}

Berilah tanda silang pada jawaban yang benar di lembar jawaban yang disediakan!

1. Untuk membuat benda hias bisa menggunakan teknik simpul yang dinamakan ....
A. Menghias
B. Merangkai
C. Meronce
D. Makrame

2. Makrame berasal dari bahasa ...
A. Arab
B. Spanyol
C. Turki
D. Inggris

3. Makrame berarti ....
A. Songketan
B. Rajutan
C. Bordiran
D. Rumbai-rumbai

4. Di bawah ini alat yang digunakan untuk pembuatan karya makrame adalah ....
A. Tali
B. Manik-manik
C. Gunting
D. Penjepit

5. Bahan utama pembuatan karya makrame ....
A. Penjepit
B. Manik-manik
C. Tali
D. Penyanggah

6. Teknik yang digunakan dalam pembuatan karya makrame adalah
A. Pilin
B. Rajut
C. Anyam
D. Simpul

7. Bahan alami untuk membuat makrame yaitu ....
A. Tali ijuk
B. Akar beringin
C. Kulit kerang
D. Kulit waru

8. Ayunan untuk bersantai yang dibuat dengan teknik makrame memiliki nilai....
A. Kecantikan
B. Keindahan saat digunakan
C. Kenyamanan
D. Keanggunan

9. Ibu Susilawati membuatan gantungan kunci dengan menggunakan bahan utama berupa tali berwarna-warni, dia menggunakan teknik ....
A. Meronce
B. Merangkai
C. Makrame
D. Menghias

10. Kita bisa membuat keranjang bola pada kerajinan makrame dengan menggunakan teknik ....
A. Simpul mati
B. Anyam
C. Pilin
D. Rajut

11. Tali yang cocok untuk makrame memiliki ciri-ciri sebagai berikut ....
A. Kuat pilinannya
B. Mulur
C. Kaku
D. Cepat mudah putus

12. Benda kerajinan makrame dapat pula dihias dengan .....
A. Manik-manik
B. Gesper
C. Bulatan-bulatan kecil
D. Semua benar

13. Bagaimana ciri-ciri tali yang cocok untuk makrame....
A. Mudah dibentuk
B. Tidak kaku
C. Tidak mudah mutus
D. Semua benar 
14. Tali jala bisa dipakai untuk......

A. Materi buatan untuk meronce

B. Materi alami untuk meronce

C. Materi buatan untuk makrame

D. Materi buatan untuk makrame

15. Penentu kualitas kerajinan makrame adalah ...
A. Material
B. Kerapian
C. Keunikan karya
D. Semua benar.

16. Di bawah ini beberapa hasil kerajinan yang dibuat dengan menggunakan teknik makrame adalah ...
A. Mantel baju
B. Keset kaki
C. Souvenir
D. Semua benar

17. Makrame termasuk kedalam jenis kerajinan ....
A. Emas dan perak
B. Kulit
C. Tekstil
D. Keramik

18.

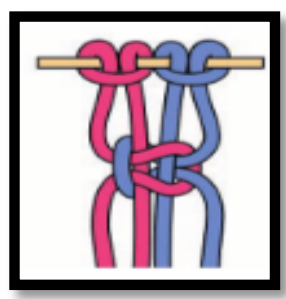

Gambar di atas merupakan salah satu gambar simpul pembuat karya makrame yaitu simpul .....
A. Kepala
B. Mati
C. Kait ganda
D. Persegi

19. Perhatikan langkah-langkah pembuatan karya makrame di bawah ini!

1. Menyiapan alat dan bahan.

2. Finishing.

3. Menyimpul tali dengan menggunakan simpul makrame.
4. Membuat desain karya.

5. Memotong tali sesuai dengan ukuran yang diinginkan.

Susunan yang benar dari langkahlangkah pembuatan karya makrame adalah ....
A. $1,4,3,5$, dan 2
B. $1,4,5,3$, dan 2
C. $4,1,3,5$, dan 2
D. $4,1,5,3$, dan 2

20. Banyak simpul yang digunkan dalam pembuatan sebuah benda hias adalah .....
A. Semua simpul
B. 3 sampai 4 simpul
C. Salah satu simpul
D. Tidak dibatasi jumlah simpul 
125 Dharma Raflesia Unib Tahun XVI, Nomor 2 Desember 2018 